\title{
Precipitação efetiva e interceptação em Caxiuanã, na Amazônia Oriental
}

\author{
Leidiane Leão de OLIVEIRA ${ }^{1}$, Rafael FERREIRA DA COSTA ${ }^{2 a}$, Francisco de Assis S. de SOUSA ${ }^{2 b}$, \\ Antonio Carlos Lôla da COSTA³ ${ }^{3}$ Alan Pantoja BRAGA ${ }^{4}$
}

\section{RESUMO}

O presente trabalho foi realizado na Estação Cientifica Ferreira Penna, dentro da Floresta Nacional de Caxiuanã, Melgaço, Pará, Brasil (01 42’ 30”S; 51 31’ 45”W; 60 m altitude). A região é uma floresta de terra firme, com vegetação densa e dossel com altura média de $35 \mathrm{~m}$ e árvores emergentes acima de $50 \mathrm{~m}$, densidade de 450 a 550 árvores por hectare. O objetivo foi o de quantificar a precipitação total incidente acima do dossel, precipitação efetiva e precipitação interna, o escoamento da água pelos troncos e interceptação da precipitação pela vegetação no período de março a dezembro de 2004, quando foram realizadas 40 coletas semanais. Na medida da precipitação interna foram utilizados 25 pluviômetros, distribuídos aleatoriamente em um hectare, subdividido em cem parcelas de 10 x $10 \mathrm{~m}$, os escoamentos pelos troncos foram medidos em sete árvores com diâmetros à altura do peito (DAP) representativos para as árvores da área. O estudo revelou uma precipitação efetiva de $905,4 \mathrm{~mm}$ e precipitação interna de $885,4 \mathrm{~mm}$, um escoamento pelos troncos de $20 \mathrm{~mm}$ e uma interceptação de $248 \mathrm{~mm}$, correspondendo, a $78,5 \%, 76,8 \%, 1,7 \%$ e $21,5 \%$ da precipitação acima do dossel, que foi de $1.153,4$ mm, no período de estudo, respectivamente.

PALAVRAS-CHAVE: Floresta tropical, interceptação, precipitação interna, escoamento pelo tronco.

\section{Net precipitation and interception in Caxiuanã, in the Eastern Amazonia}

\section{ABSTRACT}

The present work was carried out at the Ferreira Penna Scientific Station, in the Caxiuanã National Forest, Melgaço, Pará, Brazil (01'42'30"S; 51 31' 45”W; $60 \mathrm{~m}$ a.s.l.). The studied region is an upland forest with closed vegetation and a mean canopy height of $35 \mathrm{~m}$ although some trees can be $50 \mathrm{~m}$ high. The species density is between 450 and 550 plants per hectare. The aim was to quantify the net precipitation, throughfall, stemflow and rain interception by vegetation, from March to December of 2004. For the throughfall measurements 25 rain gauges were randomly distributed in an one hectare area subdivided in one hundred parcels of $10 \times 10 \mathrm{~m}$, while the stemflow was measured on seven trees with a stem diameter at breast height representative of the area. The results showed values of net precipitation of $905.4 \mathrm{~mm}$, throughfall of $885.4 \mathrm{~mm}$, stemflow 20 $\mathrm{mm}$ and rain interception of $248 \mathrm{~mm}$,corresponding respectively to $78.5 \%, 76.8 \%, 1.7 \%$ e $21.5 \%$ of the total precipitation above the canopy which was $1,153.4 \mathrm{~mm}$ for the study period.

KEY WORDS: Rain interception, stemflow, throughfall, Tropical rainforest.

\footnotetext{
1 Universidade Federal do Amapá - UNIFAP - PPGBIO, Pós-Graduação em Biodiversidade Tropical. Rodovia Juscelino Kubitscheck, km 01, S/N, Zerão, Macapá, AP, CEP 68900-280 Tel. (96) 3312-1740, leidiane.leao@iepa.ap.gov.br

2 Universidade Federal de Campina Grande - UFCG - UACA, Pós-Graduação em Meteorologia, Av. Aprígio Veloso, 882 Bloco CL, Bodocongó, Campina Grande, PB, CEP 58109-970, Tel. (83) 3310-1054, 2a, rfcostampeg@gmail.com, 2b fassis@dca.ufcg.edu.br;

3 Universidade Federal do Pará - UFPA - DM, Departamento de Meteorologia, Rua Augusto Corrêa, no01, Guamá, Belém, PA, CEP 66075-110, Tel. (91) 3201-7207, lola@ufpa.br

${ }^{4}$ Instituto Nacional de Meteorologia - INMET. Eixo Monumental Via S1, Sudoeste, Brasília, DF, CEP 70680-900. Tel. (61) 3342-1732, alan_meteoro@yahoo.com.br
} 


\section{INTRODUÇÃO}

O ciclo hidrológico tem diversas componentes, porém uma delas é desprezada em alguns estudos, a interceptação da precipitação pela vegetação. A interceptação tem grande importância no balanço hídrico, principalmente em áreas com florestas de grande porte. A influência da vegetação no recebimento e redistribuição das chuvas é significativa dentro do contexto do balanço hídrico de um determinado local.

Segundo Villela e Mattos (1975) os fatores climáticos mais importantes no balanço hidrológico de uma região são a precipitação e a evaporação. Para Tucci (2004), os processos físicos que controlam a distribuição e o movimento de água no sistema solo-planta-atmosfera são melhores compreendidos se descritos como ciclo hidrológico. A representação esquemática do ciclo hidrológico no meio ambiente natural é mostrada na Figura 1.

No estudo de uma bacia hidrográfica há uma estreita relação entre o ciclo hidrológico e a cobertura vegetal da área, interferindo no movimento hídrico das diversas etapas do sistema, inclusive nas transferências para atmosfera e cursos d'água (Arcova et al., 2003).

Em alguns casos, se confunde a quantidade de água precipitada acima do dossel, com a água realmente disponível para o solo. A falta de informação de interceptação da precipitação pela vegetação pode induzir a erros nas medidas reais das quantidades de água que contribuirão para a reposição da umidade disponível no solo, comprometendo o cálculo do balanço hídrico. Isso se deve a, que parte da precipitação em contato com a vegetação se acumula nas folhas

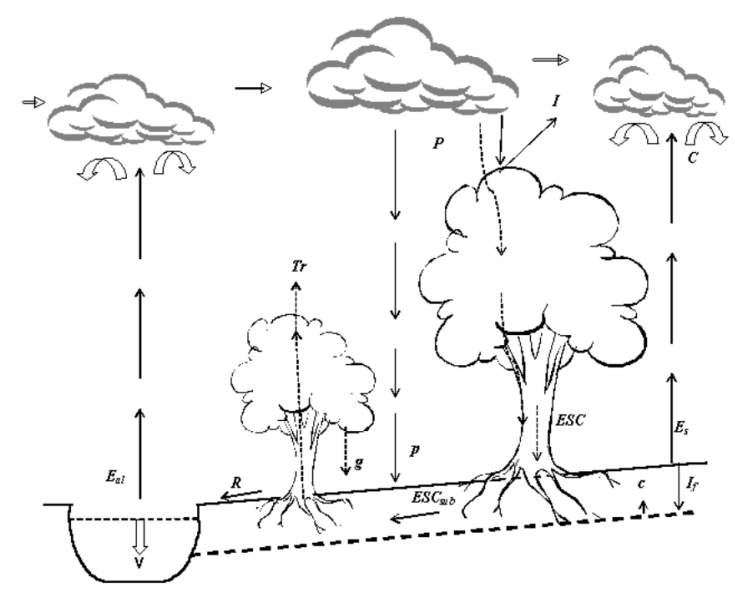

Figura 1 - Ciclo hidrológico enfatizando o processo de interceptação da precipitação pela vegetação, onde $\mathrm{P}$ é a precipitação, $\mathrm{p}$ a precipitação livre, I a interceptação, C a condensação, Tr a transpiração, Es evaporação do solo, Eal evaporação da água livre, g o gotejamento, ESC escoamento pelos troncos, R o escoamento superficial, ESCsub escoamento subterrâneo, If infiltração, c capilaridade, $\mathrm{V}$ vazão e ramos e é devolvida à atmosfera por evaporação (perdas por interceptação). Outra parte da água escorrerá pelos troncos e gotejará das folhas atingindo o solo, que somada com a parte da chuva que atravessou diretamente o dossel, formará a precipitação efetiva que realmente contribui para a recarga hídrica do solo.

De um modo geral, para florestas tropicais, as variaçōes da precipitação interna estão entre $75 \%$ e $96 \%$ da precipitação total incidente acima do dossel. A quantidade convertida em escoamento pelos troncos varia entre $1 \%$ e $2 \%$ da precipitação total incidente acima do dossel, e o total interceptado pela vegetação entre $4,5 \%$ e $24 \%$ da precipitação total incidente acima do dossel (Bruijnzeel, 1990). Contudo alguns fatores experimentais, como a distribuição dos pluviômetros e o intervalo nas coletas, também influenciam nessa partição da precipitação, dificultando a análise comparativa entre os diferentes locais pesquisados (Castro et al., 1983).

Devido a grande importância de se conhecer qual é a parcela da chuva que é interceptada pelo dossel vegetal para o sistema solo-planta-atmosfera, o objetivo deste trabalho foi quantificar e avaliar as perdas de precipitação por interceptação pela vegetação $(I)$, através das seguintes mensurações: Precipitação total incidente acima do dossel $(P)$, precipitação interna $(P I)$, precipitação efetiva $(P E)$, e o escoamento pelos troncos (ESC) na Floresta Nacional (FLONA) de Caxiuanã, Pará, Brasil, no sítio experimental do projeto Impacto da Seca Prolongada nos Fluxos de Água e Dióxido de Carbono em uma Floresta Tropical Amazônica (ESECAFLOR).

\section{MATERIAIS E MÉTODOS}

\section{LOCALIZAÇÃO E CARACTERÍSTICAS DA ÁREA DE ESTUDO}

O presente estudo foi desenvolvido na FLONA de Caxiuanã, uma floresta tropical úmida de terra firme com área de 330 mil ha, localizada no município de Melgaço, Pará, onde funciona a Estação Científica Ferreira Penna (ECFPn) que representa cerca de $10 \%$ da área da floresta, ( $01^{\circ} 42^{\prime} 30^{\prime \prime} S$; $51^{\circ} 31^{\prime} 45^{\prime \prime} \mathrm{W} ; 62 \mathrm{~m}$ de altitude). A ECFPn é administrada pelo Museu Paraense Emílio Goeldi (MPEG). Os dados foram obtidos na área experimental do ESECAFLOR, no período de janeiro a dezembro de 2004, detalhes do sítio experimental estão em Oliveira (2007).

Pela classificação de Köppen o clima da FLONA de Caxiuanã é do tipo tropical quente e úmido e subtipo climático "Am" com curta estação seca. A temperatura média do ar oscila em torno de $26,7^{\circ} \mathrm{C}\left(22^{\circ} \mathrm{C}\right.$ a $32^{\circ} \mathrm{C}$ ) (Figura 3) (Ferreira da Costa et al., 2003). O brilho de luz solar alcança 2.100 horas ano ${ }^{-1}$, com média anual de umidade relativa do ar em torno de $80 \%$. A direção do vento predominante é de nordeste (Moraes et al., 1997). 
A região de Caxiuanã tem distribuição regular das chuvas durante o ano,porém, há uma sazonalidade definida. Climatologicamente, o período chuvoso está compreendido de dezembro a junho, enquanto o seco de agosto a novembro. Para o ano de 2004, o total anual precipitado foi de 2.359 $\mathrm{mm}$, cerca de $400 \mathrm{~mm}(20,4 \%)$ acima da média do período de 1996 a 2003 que foi de $1.960 \mathrm{~mm}$. Durante o período chuvoso ocorreram $1.845 \mathrm{~mm}$ que representaram $78,2 \%$ das chuvas, enquanto no período seco, o total precipitado foi de 514,4 $\mathrm{mm}$, ou $21,8 \%$ do total anual. O mês mais chuvoso em 2004 foi março com $474 \mathrm{~mm}$ e o seco foi agosto com $40 \mathrm{~mm}$ (Figura 4). As precipitações no leste da Amazônia são influenciadas pelos oceanos Atlântico e Pacífico no primeiro trimestre do ano e as precipitaçốes acima da média estão relacionadas com os eventos de La Niña (Souza, 2003).

A FLONA de Caxiuanã agrega vários ecossistemas, dentre eles a floresta densa de terra-firme e igapó (Almeida et al., 1993). Os solos são bem a moderadamente drenados, arenosos a argilosos, ácidos e pobres em nutrientes (Ruivo et al., 2002). O pH varia de muito ácido $(3,5)$ a moderadamente ácido $(5,5)$.

Viana et al. (2003) descrevem na área da ECFPn 85\% de floresta de terra-firme. A fisionomia florestal é formada por árvores emergentes com alturas que variam de 40 a $50 \mathrm{~m}$, o dossel médio por árvores com alturas entre 30 e 35 m, um sub-dossel com 20 a $25 \mathrm{~m}$ de altura e o piso com altura em torno de $5 \mathrm{~m}$. A diversidade de espécies está entre 150 a 160 $\mathrm{ha}^{-1}$ e a densidade de indivíduos varia de 450 a 550 árvores $\mathrm{ha}^{-1}$. As espécies predominantes nessa floresta de terra-firme são a Eschweilera coriacea (Lecythidaceae), Voucapoua americana (Caesalpiniaceae) e Protium pallidum (Burseraceae). Silva, et al., (2003) registraram até o ano de 2003, 1.054 espécies pertencentes a 393 gêneros e 102 famílias. As espécies arbóreas (663) são predominantes $(62,9 \%)$.

\section{MÉTODOS E INSTRUMENTAÇÕES UTILIZADAS}

O experimento foi realizado de janeiro a dezembro de 2004, quando foram feitas 53 coletas semanais. Devido a problemas nos interceptômetros para medidas do escoamento pelos troncos, somente as informaçōes de 40 coletas foram efetivamente utilizadas para os cálculos da interceptação da precipitação pela vegetação, entre 18 de março e 30 de dezembro. Como não há possibilidade de medir diretamente a interceptação foi adotada a seguinte nomenclatura: a água coletada no topo da torre micrometeorológica acima da cobertura vegetal, foi denominada de precipitação total acima do dossel $(P)$; a precipitação interna $(P I)$ foi a parte da água drenada pelo dossel e que chegou ao solo por gotejamento, somada à parte que atingiu diretamente a superfície atravessando a cobertura vegetal $(p)$; o escoamento pelo tronco (ESC) foi a parcela da precipitação desviada pela vegetação e drenada pelos galhos e troncos; a interceptação da precipitação pela vegetação $(I)$ foi a quantidade de água retida na superfície das folhas, troncos e ramos e depois evaporada, retornando à atmosfera. A descrição do processo de interceptação é apresentada na figura 2. P é medida acima do nível superior do dossel ou fora da zona de influência das copas das árvores; $P I$ e o $E S C$ são mensurados abaixo do dossel e a soma de todas essas partes forma a precipitação efetiva $(P E)$.

Horton (1919) já utilizava pluviômetros e interceptômetros em áreas com vegetação adulta na tentativa de comprovar que a quantidade de chuva que chegava ao solo sob áreas florestadas ou cultivos agrícolas desenvolvidos, era menor do que o total medido em áreas abertas ou acima da vegetação. Nesse estudo pioneiro, o autor lançou as bases das técnicas de medidas experimentais da interceptação da precipitação pela vegetação com a distribuição de diversos pluviômetros em diferentes situações e posiçôes e interceptômetros artesanais para determinar o escoamento pelos troncos. Ainda hoje suas técnicas são aplicadas com algumas modificaçōes propostas pelas novas tecnologias desenvolvidas.

No presente estudo, utilizou-se uma parcela aproximadamente quadrada. Esse formato da parcela permite o fácil acesso ao interior da área sem os conseqüentes danos à vegetação rasteira, além de incluir um grande número de árvores dominantes (Lloyd e Marques Filho, 1988). Uma área de 1 ha representativa da floresta tropical de terra firme foi demarcada e dividida em subparcelas de $10 \mathrm{~m}$ de comprimento por $10 \mathrm{~m}$ de largura, com cem posiçôes possíveis de coleta. A área selecionada representa bem a morfologia, a diversidade e a densidade de indivíduos no hectare. Foram catalogados 526 exemplares vegetais com diâmetro à altura do peito (DAP) maior que $0,1 \mathrm{~m}$. As árvores foram divididas em oito diferentes classes de acordo com o DAP. A primeira classe reuniu exemplares com DAP entre 0,1 e $0,2 \mathrm{~m}$, e foi a mais

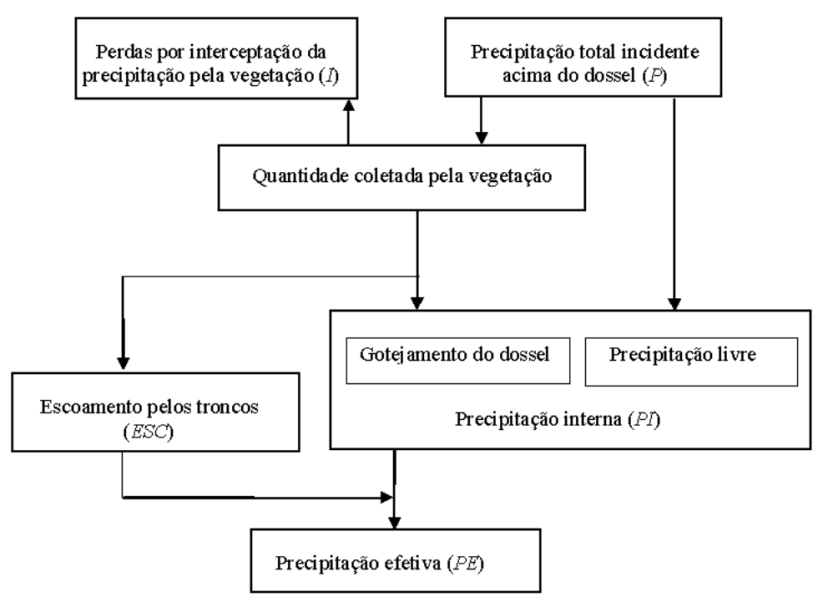

Figura 2 - Fluxograma conceitual do processo de interceptação da precipitação pela vegetação e a precipitação que efetivamente chega ao solo 
representativa do grupo com 308 indivíduos, significando $58,5 \%$ do total de árvores identificadas na parcela. Esta e as demais classes são apresentadas na Tabela 1. A classificação das árvores é necessária para a determinação dos exemplares nos quais seriam instalados os interceptômetros para a medida do escoamento pelos troncos. As três primeiras classes; $0,1 \mathrm{~m}$ $<$ DAP $<0,2 \mathrm{~m} ; 0,2 \mathrm{~m}<\mathrm{DAP}<0,3 \mathrm{~m} ; 0,3 \mathrm{~m}<\mathrm{DAP}<0,4$ $\mathrm{m}$ reuniram 487 exemplares de vegetais, o que representou $92,5 \%$ da população total. Germer et al. (2006) estudando a redistribuição de chuva pela vegetação no sítio Rancho Grande, próximo a Ariquemes, Rondônia, no Sudoeste da Amazônia, identificaram 520 árvores por hectare com DAP $>0,1 \mathrm{~m}$. Dessa forma foram selecionadas sete árvores para a instalação dos interceptômetros, quatro na classe $1(0,1 \mathrm{~m}<$ DAP $<0,2 \mathrm{~m})$, duas na classe dois $(0,2 \mathrm{~m}<\mathrm{DAP}<0,3 \mathrm{~m})$, e uma na classe três $(0,3 \mathrm{~m}<\mathrm{DAP}<0,4 \mathrm{~m})$, os detalhes dessas árvores também são apresentados na tabela 1 .

\section{PRECIPITAÇÃO TOTAL INCIDENTE ACIMA DO DOSSEL}

Devido à disponibilidade da torre micrometeorológica $(52$ $m$ de altura) instalada em Caxiuanã (Figura 3A), a cerca de 2 $\mathrm{km}$ ao norte da área do experimento, a medida da precipitação acima da vegetação foi feita nesse local. Um pluviógrafo do tipo CSI Model CS700-L, Rain Gage, com 314,2 $\mathrm{cm}^{2}$ de área de captação e capacidade basculante de $100 \mathrm{~mm} \mathrm{~h}^{-1}$ (Figura 3B) foi utilizado para a coleta.

Tabela 1 - Classificação das árvores da parcela $A$ por classe. Diâmetro à altura do peito (DAP), quantidade de exemplares e percentuais, e DAP das árvores com interceptômetros

\begin{tabular}{cccccc}
\hline Classes & $\begin{array}{c}\text { DAP } \\
(\mathrm{m})\end{array}$ & $\begin{array}{c}\text { Quantidade } \\
\text { de } \\
\text { exemplares }\end{array}$ & $\begin{array}{c}\text { (\%) } \\
\text { Interceptômetros } \\
\text { No. }\end{array}$ & DAP $(\mathrm{m})$ \\
\hline 1 & $\begin{array}{c}0,100 \mathrm{a} \\
0,200\end{array}$ & 308 & 58,5 & 1 & 0,122 \\
\hline 2 & $\begin{array}{c}0,201 \mathrm{a} \\
0,300\end{array}$ & 120 & 22,8 & 2 & 0,327 \\
\hline 3 & $\begin{array}{c}0,301 \mathrm{a} \\
0,400\end{array}$ & 59 & 11,2 & 3 & 0,125 \\
\hline 4 & $\begin{array}{c}0,401 \mathrm{a} \\
0,500\end{array}$ & 14 & 2,7 & 4 & 0,111 \\
\hline 5 & $\begin{array}{c}0,501 \mathrm{a} \\
0,600\end{array}$ & 14 & 2,7 & 5 & 0,122 \\
\hline 6 & $\begin{array}{c}0,601 \mathrm{a} \\
0,700\end{array}$ & 3 & 0,6 & 6 & 0,229 \\
\hline 7 & $\begin{array}{c}0,701 \mathrm{a} \\
0,800\end{array}$ & 3 & 0,6 & 7 & 0,272 \\
\hline 8 & $\begin{array}{c}> \\
0,800\end{array}$ & 5 & 1,0 & & \\
\hline Total & & 526 & 100 & 7 & 1,308 \\
\hline
\end{tabular}

\section{PRECIPITAÇÃO INTERNA}

Nos estudos de interceptação da precipitação pela vegetação, essa variável requer enorme atenção na sua obtenção. Na bibliografia consultada os autores destacam a necessidade de elevado número de pluviômetros. Holwerda et al. (2006) concluíram que são necessários cem pluviômetros fixos para se obter resultado similar ao obtido com trinta pluviômetros móveis, com nível de confiança de $95 \%$. Neste estudo foram utilizados 25 coletores alternativos, construídos com garrafas "pets" para armazenar dois litros de água, acopladas a funis de alumínio com área de captação de $153,94 \mathrm{~cm},{ }^{2}$ com um suporte de madeira, que foram nivelados a $1 \mathrm{~m}$ acima do solo (Figura 3C). Os pluviômetros foram distribuídos aleatoriamente dentro da área experimental e dispostos no centro de cada célula, com distância média entre eles de 10 $\mathrm{m}$. A coleta foi feita semanalmente com o auxílio de proveta graduada em mililitros. Para o cálculo da altura de PI foi utilizada a seguinte relação:

$$
P I=\frac{V l}{A f}
$$

onde PI é a quantidade de chuva expressa em ( $\mathrm{mm}), V l o$ volume em litros de chuva na proveta e $A f$ a área de captação do funil $\mathrm{em} \mathrm{m}^{2}$. A precipitação interna foi obtida pela média dos 25 pluviômetros em cada coleta.

Foi utilizado o processo de amostragem aleatória, com os coletores trocados aleatoriamente após cada coleta, para evitar o viciamento das medidas e possibilitar melhores resultados, e não usar as posições fixas na parcela, método aplicado por Helvey e Patrick (1965) apud Ubarana (1994). Toda semana foi realizado um sorteio para definir as novas posições. Dessa forma espera-se que haja redução do erro nas medidas de $P I$. Durante as 40 coletas semanais, todas as cem subparcelas possíveis para a localização dos 25 pluviômetros foram utilizadas. As subparcelas com menor número de repetiçôes foram, a 44 (1 vez), a 29 (2 vezes) e as subparcelas 7 e 9, com 3 repetiçóes cada uma. As subparcelas mais utilizadas foram, a 35 com 21 repetiçóes, as subparcelas 15 e $61 \mathrm{com}$ 18 repetiçôes cada uma, e as subparcelas 30 e 69 com 17 repetições cada uma.

\section{ESCOAMENTO PELOS TRONCOS}

Para obter o escoamento pelos troncos, foram escolhidas sete árvores com DAP representativos da parcela, em cada uma dessas árvores foi montado um coletor na altura do peito $(1,3 \mathrm{~m})$ em forma de anel de alumínio acoplado ao tronco e vedado com uma faixa de borracha flexível. Uma mangueira plástica com 0,019 m (3/4") ligou o anel ao recipiente no solo. A capacidade do recipiente foi de 10 litros (Figura 3D). 
O escoamento pelo tronco foi calculado pela equação (2):

$$
E S C=(V e / P c) *(P c a / A t)
$$

onde $E S C=$ Escoamento pelo tronco $(\mathrm{mm}) ; V e=$ Volume total escoado pelos troncos (litros); $P c=$ Perímetro das árvores com os interceptômetros (m); $P c a=$ Perímetro total dos caules (m); $A t=$ Área total $\left(\mathrm{m}^{2}\right)$. A componente $E S C$ foi totalizada integrando-se os valores das sete árvores.

\section{INTERCEPTAÇÃO DA PRECIPITAÇÃO PELA VEGETAÇÃO}

Após a obtenção dos dados, calculou-se $I$ empregando-se as equaçôes a seguir:

$$
I=P-P E
$$

A precipitação que efetivamente chega ao solo foi calculada de acordo com a equação abaixo:

$$
P E=P I+E S C
$$

Aplicando a equação (4) em (3), tem-se:

$$
I=P-(P I+E S C)
$$

onde $I=$ Perdas por interceptação; $P=$ Precipitação acima do dossel; $P I=$ Precipitação interna; $P E=$ Precipitação efetiva; $E S C=$ Escoamento pelo tronco (todos $\mathrm{em} \mathrm{mm}$ ) (Horton, 1919; Rutter et al., 1971, 1975, Gash, 1979; Gash et al., 1995; Ubarana, 1994, 1996, Ferreira et al., 2005 e Germer et al., 2006).

\section{RESULTADOS E DISCUSSÃO}

Em estudos de interceptação, principalmente os realizados em florestas tropicais, na prática é usado o método que integra os totais de precipitação de um período com alguns dias ou semanas (Jackson 1971 e Ubarana 1994). Porém, segundo Lima (1998), a maneira ideal seria a quantificação das perdas por interceptação após cada evento de chuva, entretanto, no campo isso é impossível, sobretudo em áreas tropicais como em Caxiuanã que tem uma distribuição regular das chuvas (Figura 4), e que no ano de 2004 ocorreram 343 eventos
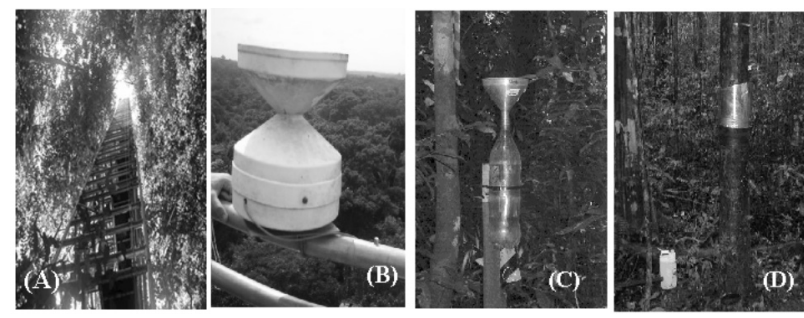

Figura 3 - Instrumentos utilizados no estudo de interceptação da precipitação pela vegetação. (A) Torre micrometeorológica. (B) Pluviógrafo instalado no topo da torre. (C) Pluviômetro artesanal para medir a precipitação interna, instalado a $1 \mathrm{~m}$ do solo. (D) Interceptômetro instalado em uma das árvores representativas da área de precipitação com volumes superiores a $1,6 \mathrm{~mm} \mathrm{~h}^{-1}$, essa é uma das razões que dificultam a leitura após cada evento de chuva.

A precipitação direta $(P)$ totalizou $1.153,4 \mathrm{~mm}$, considerando-se apenas os eventos de chuva superiores a 1,6 $\mathrm{mm} \mathrm{h}^{-1}$, pois quantidades de chuva inferiores a esse valor são interceptadas pelo dossel e evaporadas. Este total foi redistribuído na forma de precipitação interna $(P I)$ 885,4 mm $(76,8 \%$ de $P)$, de escoamento pelos troncos (ESC) 20,0 $\mathrm{mm}(1,7 \%$ de $P)$ e de precipitação efetiva $(P E)$ de $905,4 \mathrm{~mm}$ $(78,5 \%$ de $P)$. As perdas por interceptação $(I)$ totalizaram 248 mm $(21,5 \%$ de $P)$. Na Tabela 2 são apresentados os valores de P, PI, ESC, PE e I.

\section{PRECIPITAÇÃO INTERNA}

A precipitação interna $(P I)$ atingiu um volume total de $885,4 \mathrm{~mm}$. Este valor representou $76,8 \%$ da precipitação total incidente acima do dossel $(P)$ e está em concordância com diversos outros trabalhos desenvolvidos para a região amazônica, como por exemplo, os realizados por Franken et al. (1982a; 1982b) no Amazonas, que encontraram 77,7\% para a estação da Bacia Modelo, no km 14 da ZF-2, e 80,2\% para a Reserva Florestal Ducke. Ferreira et al. (2005) ao estudarem uma área de floresta preservada no $\mathrm{km} 23 \mathrm{da}$ ZF-2 definiram uma precipitação interna que representou 80,8\% precipitação total. Ubarana (1996) encontrou valores maiores

Tabela 2 - Valores da precipitação total incidente acima do dossel (P), precipitação interna $(\mathrm{PI})$, escoamento pelos troncos (ESC) e perdas por interceptação (I) em Caxiuanã, Pará para o período de 18 de março a 30 de dezembro 2004 em (mm) e (\% de P)

\begin{tabular}{llllllllll}
\hline & $\mathrm{P}$ & $\mathrm{PI}$ & & $\mathrm{ESC}$ & $\mathrm{PE}$ & & $\mathrm{I}$ & \\
\hline & $(\mathrm{mm})$ & $(\mathrm{mm})$ & $(\%)$ & $(\mathrm{mm})$ & $(\%)$ & $(\mathrm{mm})$ & $(\%)$ & $(\mathrm{mm})$ & $(\%)$ \\
Total & $1.153,4$ & 885,4 & 76,8 & 20,0 & 1,7 & 905,4 & 78,5 & 248,0 & 21,5 \\
\hline
\end{tabular}

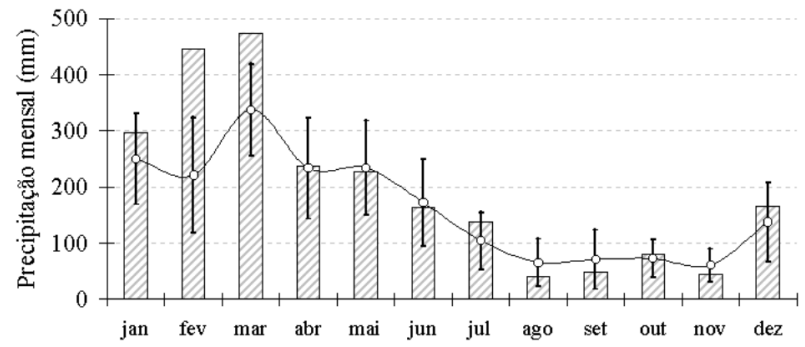

Figura 4 - Precipitação mensal total acima do dossel em 2004. Os círculos representam as médias mensais e as linhas verticais os desvios-padrão no período de 1996 a 2003, para a FLONA de Caxiuanã, Pará 
de precipitação interna que representaram $86,3 \%$ do total na Reserva Vale do Rio Doce, no sudeste do Pará e, $87 \%$ para a Reserva Biológica do Jarú, nordeste de Rondônia, isto devido às grandes quantidades de palmeiras naquelas áreas. Em outro estudo, Germer et al. (2006), encontraram uma precipitação interna que significou $89,8 \%$ da precipitação total para uma Floresta Ombrófila Aberta com grandes quantidades de palmeiras de babaçu (Orbignya phalerata). Dos trabalhos supracitados, os maiores valores de precipitação interna em ralação a precipitação total foram encontrados para sítios experimentais em Rondônia (87\%, Ubarana, 1996, e 89,8\%, Germer et al. 2006), em ambos os casos, a responsável pelos elevados valores de precipitação interna foi a grande presença de palmeiras que constituem a vegetação naqueles locais, pois o formato das folhas desse tipo de planta proporciona maiores espaços no dossel superior, o que permite maior penetração direta da precipitação que atinge o solo. Na comparação entre todos esses estudos, nota-se claramente que a precipitação interna contribui com a maior parte da água que atinge a superfície, diferenciando apenas pela formação das folhas do dossel superior de cada uma das regiôes analisadas.

A Figura $5 \mathrm{~A}$ mostra que cerca de $95 \%$ da precipitação interna pode ser explicada pela precipitação total acima do dossel. Isso mostra como a precipitação interna é altamente relacionada com a precipitação total como descrito pelo modelo de regressão linear. Por meio da equação de regressão $P I=0,8127(P)-1,2993$, estimou-se que as precipitaçōes inferiores à cerca de 1,6 mm são totalmente interceptadas pela cobertura vegetal e devolvidas à atmosfera por evaporação. Valores similares foram estimados em outros estudos como: 2,1 mm para Pinus Radiata no Chile (Huber e Oyarzún, 1992), 1,4 mm para mata ciliar na região central de São Paulo (Lima, 1998; Lima e Leopoldo, 1999), e 1,3 mm para um fragmento secundário de mata Atlântica no Estado de Minas Gerais (Oliveira Júnior e Dias, 2005).

\section{ESCOAMENTO PELO TRONCO}

Apesar de ser até negligenciado por alguns autores por significar pequenos percentuais (em torno de 1 a $5 \%$ dos totais precipitados) (Horton, 1919; Lima e Nicolielo, 1983), o escoamento pelos troncos tem importância no ciclo hidrológico por ser eficiente na reposição de água no solo, pois chega à superfície com baixa velocidade devido ao atrito com a casca dos vegetais, e se direciona próximo às raízes o que reduz o escoamento superficial. Essa água infiltra mais facilmente no solo e favorece o reabastecimento do lençol freático.

O escoamento pelos troncos obtido em Caxiuanã foi de $20,0 \mathrm{~mm}$ e representou $1,7 \%$ da precipitação medida acima do dossel florestal. Esse valor aproxima-se do encontrado por Leopoldo et al. (1987) e por Lloyd \& Marques Filho (1988) de 1,8\% para a Reserva Florestal Ducke em Manaus. Já Ubarana (1996) encontrou valores menores, 1,4\% para a
Reserva Biológica do Jarú, e 0,8\% na Reserva Vale do Rio Doce. Lima (1998) e Lima e Leopoldo (1999) obtiveram valores de 0,9 e 3,0\% para o extrato superior e o sub-dossel, respectivamente, de uma mata ciliar com área de 3 hectares em São Paulo. No sítio experimental Rancho Grande, Germer et al. (2006) encontraram um escoamento pelos troncos que representou $7,8 \%$ da precipitação total, segundo os autores, esse valor elevado foi devido aos formato afunilado das folhas das palmeiras, pois alguns interceptômetros foram instalados nessa variedade vegetal que tem participação significativa na composição do dossel local.

O valor de escoamento pelos troncos, que foi aparentemente pequeno, $20 \mathrm{~mm}$ e que representou $1,7 \%$ da precipitação total incidente acima do dossel, não deve ser negligenciado, pois tem importância na velocidade e quantidade da água que atingirá o solo florestal e permite boa infiltração além de reduzir a incidência de escoamento superficial (runoff). Isto tem maior importância durante os períodos secos. (Price, 1982; Huber e Oyarzún, 1983; Johnson, 1990).

A Figura 5B mostra que a relação entre a precipitação total e o escoamento pelos troncos é apenas regular $\left(R^{2}=0,56\right)$ com regressão linear $E S C=0,0222 P-0,1387$. Essa equação estimou que valores de precipitaçóes inferiores a $6,2 \mathrm{~mm} \mathrm{~h}^{-1}$ são desviados para os troncos, retidos e devolvidos à atmosfera por evaporação e não alcançam a superfície do terreno. $O$ valor da capacidade de retenção da chuva pelos troncos encontrado neste trabalho está dentro do intervalo obtido em outros estudos como os 8,5 mm de Leopoldo (1981) na Amazônia central, de Huber e Oyarzún (1983 e 1992) que calcularam 6,0 e 5,1 mm, respectivamente em Pinus Radiata, no Chile. Assim como o encontrado para mata ciliar em São Paulo por Lima (1998) e, Lima e Leopoldo (1999) que obtiveram o menor valor de 4,2 $\mathrm{mm}$. Porém, foi muito abaixo de $11,3 \mathrm{~mm}$ que Oliveira Júnior e Dias (2005) determinaram em fragmento de mata Atlântica em Minas Gerais devido, provavelmente às características desse tipo de vegetação.

\section{PRECIPITAÇÃO EFETIVA}

A precipitação efetiva foi de $905,4 \mathrm{~mm}$, o que correspondeu a $78,5 \%$ da precipitação total incidente em Caxiuanã. Esse percentual está dentro do intervalo obtido em trabalhos anteriores desenvolvidos na Amazônia, como os 78,0\% obtidos por Franken et al. (1982a) no Amazonas e Ubarana (1996) que encontrou precipitação efetiva de $87,1 \%$ no sudeste do Pará e de $88,4 \%$ para o nordeste de Rondônia. Entretanto ficou abaixo dos $97,6 \%$ determinados por Germer et al. (2006) em Rondônia, mais uma vez um valor elevado devido à presença de palmeiras na vegetação local.

Como esperado, ocorreu alta correlação linear entre a precipitação efetiva e a precipitação total com $R^{2}=0,9539$ (Figura 5C). Isso mostra o efeito linear das variáveis, 
precipitação interna e escoamento pelo tronco em virtude da precipitação total incidente.

\section{INTERCEPTAÇÃO DA PRECIPITAÇÃO PELA VEGETAÇÃOO}

A interceptação da precipitação pela vegetação foi de $248 \mathrm{~mm}$ que representou $21,5 \%$ da precipitação total, é um valor significativo para região. Este valor é comparável com os $22 \%$ e os $19,8 \%$ obtidos por Franken et al (1982a; 1982b), respectivamente, assim como os $21,3 \%$ encontrados por Leopoldo et al.(1987), ou os 19,2\% determinados por Ferreira et al. (2005), todos no Estado do Amazonas. Esta proximidade nos valores da interceptação é devida às características similares das vegetaçôes nas áreas estudadas. Porém, novamente, Germer et al. (2006), devido às palmeiras existentes em Rondônia, encontraram interceptação de apenas $2,4 \%$ da precipitação total.

A contribuição do processo de interceptação da precipitação pela vegetação para o ciclo hidrológico da região da FLONA de Caxiuanã mostra-se bastante significativa. Considerando-se uma precipitação de 1.153,4 mm, estimou-se que em média $248,0 \mathrm{~mm}$ foram interceptados pela cobertura vegetal da floresta e retornaram à atmosfera para fazer parte da massa de vapor d'água da região. Como a vegetação já contribui na redução do impacto das gotas das chuvas sobre o solo e diminui os danos ao solo causado pela erosão com o conseqüente assoreamento dos leitos dos igarapés e rios da

A

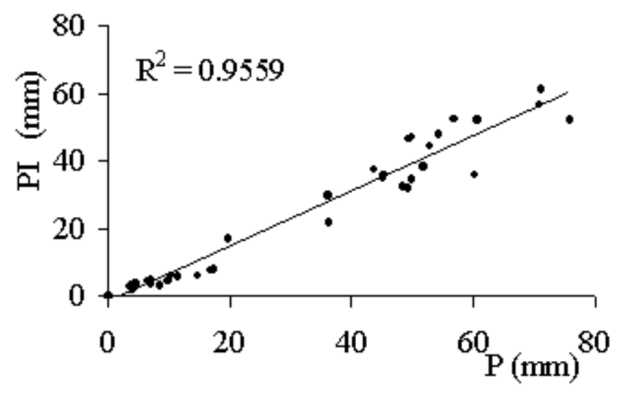

$\mathrm{C}$

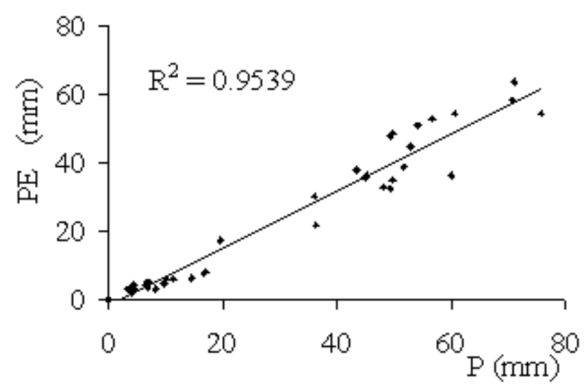

bacia hidrográfica local, a interceptação é mais uma importante função da vegetação de grande porte na Amazônia.

Nas Figuras 5A e 5C, as correlaçôes entre as precipitações total, interna e efetiva mostraram grande interdependência entre elas. Já nas correlações entre a precipitação total, o escoamento e a interceptação (Figuras 5B e 5D) a dependência da magnitude da chuva acima do dossel é reduzida, mas verificam-se graus importantes de suas intensidade e duração. $\mathrm{Na}$ figura 5D a interceptação apresentou fraca correlação com a precipitação total $\left(R^{2}=0,45\right)$ como indica o modelo de regressão linear $I=0,1651(P)+1$,438. Isto significa que a interceptação tem capacidade máxima de retenção, não importando o total precipitado, se os grandes volumes da estação chuvosa ou as chuvas mais irregulares da estação seca, pois, assim que a interceptação máxima é atingida, começa o gotejamento.

Os totais acumulados $(\mathrm{mm})$ da precipitação interna $(P I)$, precipitação efetiva $(P E)$ e interceptação da precipitação pela vegetação $(I)$, acompanharam a variação da precipitação total incidente acima do dossel $(P)$ em todo período analisado de 2004 (Figura 6). Para Oliveira Júnior e Dias (2005) os valores de precipitação total e precipitação efetiva podem ser diferentes, principalmente em virtude da quantidade, diversidade e idade de espécies, nível de inclusão do diâmetro à altura do peito, tipo de coletor de escoamento pelo tronco, arquitetura e forma de copa, estratificação das copas, filotaxia,

B

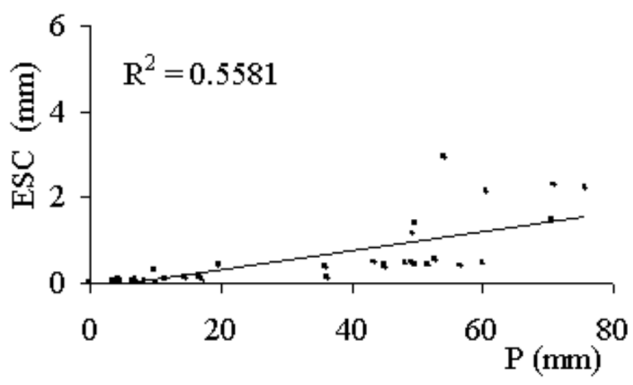

D

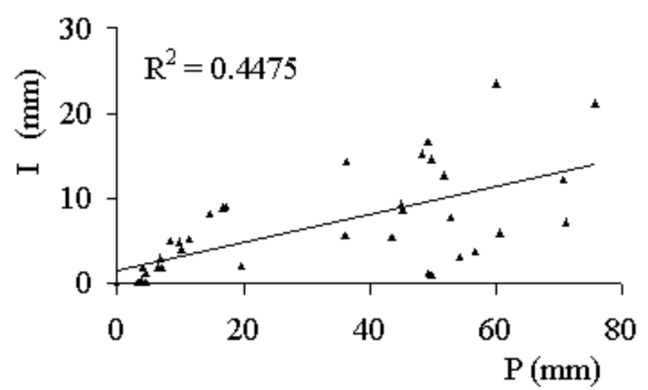

Figura 5 - Correlações entre a precipitação total incidente acima do dossel $(P)$ e as variáveis; (A) precipitação interna $(P I)$, (B) escoamento pelo tronco (ESC), (C) precipitação efetiva $(P E)$, (D) Interceptação (I) em Caxiuanã, Pará, no período de 18 de março 30 de dezembro de 2004 
tipo de folha, tamanho e forma da folha, tipo de casca e irregularidades no tronco.

Observa-se claramente o crescimento do volume precipitado acima do dossel entre os meses de março a junho (período chuvoso) quando a precipitação total ultrapassou 700 $\mathrm{mm}$, o que reflete diretamente nas variações de precipitação interna maior que $580 \mathrm{~mm}$ e de precipitação efetiva que praticamente alcançou $600 \mathrm{~mm}$. A interceptação atingiu os $100 \mathrm{~mm}$ nesse período chuvoso. Para o segundo semestre de 2004 (período seco), nota-se redução acentuada na intensidade de precipitação total em torno dos $230 \mathrm{~mm}$ o que influenciou na precipitação interna e na precipitação efetiva que oscilaram em torno de $140 \mathrm{~mm}$. Nesse período seco, o escoamento pelos troncos foi menor que $2 \%$ da precipitação total, pois as ocorridas no período seco são em geral, de baixa intensidade, sofrendo interceptação e evaporação.

A interceptação de aproximadamente $95 \mathrm{~mm}$ no período seco permaneceu na mesma magnitude do período chuvoso, porém, como a precipitação total reduziu de $700 \mathrm{~mm}$ (chuvoso) para $230 \mathrm{~mm}$ (seco), a importância da interceptação aumenta, pois, um percentual muito maior da chuva que atingiu a parte superior da vegetação, foi reciclado na forma de vapor para atmosfera. Isso contribui para a manutenção do ciclo hidrológico que mantém a floresta amazônica com suas características atuais.

Os resultados obtidos nesse estudo são similares aos obtidos em diversos estudos realizados na Amazônia brasileira desde a década de 1980 (Tabela 3). A maioria dos estudos usados para comparação foi realizada nas áreas de florestas próximas à Manaus, principalmente na ZF-2 e na Reserva Ducke (Franken et al.1982a, 1982b; Leopoldo et al.,1987 e, Ferreira et al., 2005). Outros foram desenvolvidos em Rondônia (Ubarana, 1996; Germer et al., 2006), e este é o

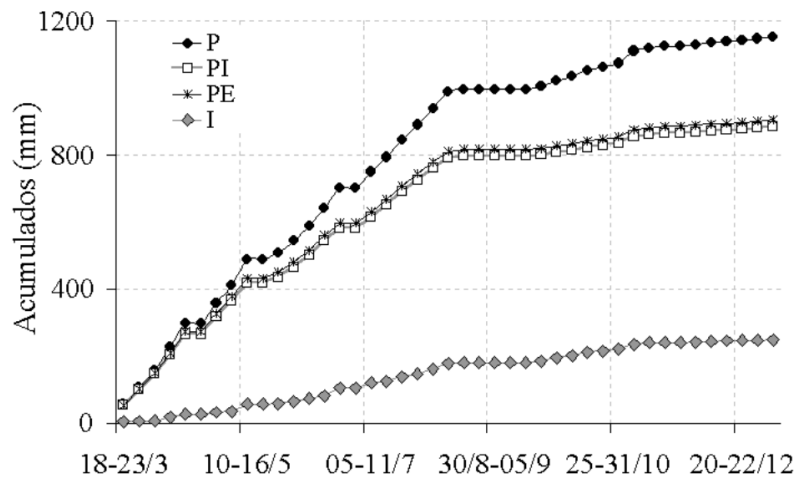

segundo no Pará (Ubarana, 1996) e o primeiro para a FLONA de Caxiuanã.

Os modelos matemáticos obtidos pelas correlações lineares entre as variáveis estudadas são apresentados na tabela 4. Há correlaçôes moderadas entre o escoamento pelos troncos e a interceptação com a precipitação total o que mostra a possibilidade de estimativas regulares dos valores de escoamento pelos troncos e da interceptação tendo apenas a informação da chuva ocorrida acima do dossel. Nota-se também que há fortes correlações entre as precipitações

Tabela 3 - Comparativo dos valores (\%) obtidos de precipitação interna (PI), interceptação (I) e escoamento pelos troncos (ESC) para estudos realizados em diferentes sítios experimentais na Amazônia brasileira

\begin{tabular}{lcccl}
\hline Local & PI (\%) & I (\%) & ESC & Autor \\
\hline $\begin{array}{l}\text { Bacia Modelo, } \\
\text { ZF-2, km 14 (AM) }\end{array}$ & 77,7 & 22,0 & 0,3 & Franken et al. (1982a) \\
$\begin{array}{l}\text { Reserva Florestal } \\
\text { Ducke (AM) }\end{array}$ & 80,2 & 19,8 & - & Franken et al. (1982b) \\
$\begin{array}{l}\text { Bacia Modelo, } \\
\text { ZF-2, km 14 (AM) }\end{array}$ & - & 25,6 & - & Schubart et al. (1984) \\
$\begin{array}{l}\text { Bacia Modelo, } \\
\text { ZF-2, km 14 (AM) }\end{array}$ & 78,4 & 21,3 & 0,3 & Leopoldo et al. (1987) \\
$\begin{array}{l}\text { Reserva Florestal } \\
\text { Ducke (AM) }\end{array}$ & 89,3 & 8,9 & 1,8 & Leopoldo et al. (1987) \\
$\begin{array}{l}\text { Reserva Florestal } \\
\text { Ducke (AM) }\end{array}$ & 91,0 & 7,2 & 1,8 & $\begin{array}{l}\text { Lloyd e Marques Filho } \\
\text { (1988) }\end{array}$ \\
$\begin{array}{l}\text { Reserva Vale do } \\
\text { Rio Doce (PA) }\end{array}$ & 86,2 & 12,9 & 0,8 & Ubarana (1996) \\
$\begin{array}{l}\text { Reserva Biológica } \\
\text { do Jarú (R0) }\end{array}$ & 87,0 & 11,6 & 1,4 & Ubarana (1996) \\
$\begin{array}{l}\text { Floresta Intacta, } \\
\text { ZF-2, km 23 (AM) }\end{array}$ & 80,8 & 19,2 & - & Ferreira et al. (2005) \\
$\begin{array}{l}\text { Floresta aberta } \\
\text { Rancho Grande } \\
\text { (R0) }\end{array}$ & 89,8 & 2,4 & 7,8 & Germer et al. (2006) \\
$\begin{array}{l}\text { Floresta Nacional } \\
\text { Caxiuanã (PA) }\end{array}$ & 76,8 & 21,5 & 1,7 & Este estudo \\
\hline
\end{tabular}

Tabela 4 - Modelos matemáticos obtidos pelas regressões lineares entre a precipitação acima do dossel $(P)$ e as variáveis; Precipitação interna $(P I)$, Precipitação efetiva $(P E)$, escoamento pelos troncos $(E S C)$, e interceptação $(I)$, durante quarenta coletas semanais de 18 de março a 30 de dezembro de 2004

\begin{tabular}{lll}
\hline Variáveis correlacionadas & Modelos matemáticos & $\mathrm{R} 2$ \\
\hline Precipitação interna & $\mathrm{PI}=0,8127(\mathrm{P})-1,2993$ & 0,9559 \\
Precipitação efetiva & $\mathrm{PE}=0,8349(\mathrm{P})-0,9539$ & 0,9539 \\
Escoamento pelos troncos & $\mathrm{ESC}=0,0222(\mathrm{P})-0,1387$ & 0,5581 \\
Interceptação & $\mathrm{I}=0,1651(\mathrm{P})+1,438$ & 0,4475
\end{tabular}

Figura 6 - Valores semanais acumulados $(\mathrm{mm})$ da precipitação total incidente acima do dossel $(P)$, precipitação interna $(P I)$, precipitação efetiva $(P E)$ e interceptação da precipitação pela vegetação $(I)$, em Caxiuanã, Pará, entre março e dezembro de 2004 
interna e efetiva e a precipitação total o que indica ser possível estimar com bom grau de confiabilidade seus valores a partir da precipitação total incidente acima da vegetação.

\section{CONCLUSÕES}

O estudo ressalta a importância da determinação da magnitude da precipitação interceptada pela vegetação para análises de balanço hídrico visto que a interceptação é parte significativa da precipitação total incidente acima do dossel.

Na FLONA de Caxiuanã, em relação à precipitação total acima do dossel que foi de $1.153,4 \mathrm{~mm}$ entre março e dezembro de 2004; a interceptação de $248 \mathrm{~mm}$ correspondeu a $21,5 \%$; a precipitação efetiva de $905,4 \mathrm{~mm}$ representou $78,5 \%$; a precipitação interna de $885,4 \mathrm{~mm}$ significou $76,8 \%$ e o escoamento pelos troncos de $20 \mathrm{~mm}$ correspondeu a 1,7\%. Os resultados encontrados foram próximos aos obtidos em diversos estudos realizados na Amazônia.

Os dados mostraram que a interceptação quase não variou durante o ano, porém, como a precipitação total no período seco tem grande redução, a importância da interceptação da precipitação pela vegetação aumenta. A precipitação interna éo mais importante componente do processo de interceptação em termos percentuais. Também percentualmente, o escoamento pelos troncos é considerado pequeno quando comparado ao valor da precipitação interna, porém de grande importância, pois durante o período seco, quando as chuvas diminuem de intensidade e freqüência, este volume escoado pelos troncos funciona como mecanismo de auto-abastecimento de água no solo.

\section{AGRADECIMENTOS}

Os autores agradecem a Coordenação de Aperfeiçoamento de Pessoal de Nível Superior - CAPES as bolsas de Pósgraduação. Agradecem também aos colegas envolvidos nas atividades de campo em Caxiuanã.

\section{BIBLIOGRAFIA CITADA}

Almeida, S.S.; Lisboa, P.L.B.; Silva, A.S.L. 1993. Diversidade florística de uma comunidade arbórea na Estação Científica Ferreira Penna, Caxiuanã, Pará. Boletim Museu Paraense Emílio Goeldi, série botânica, Belém, v.9, n.1, p.99-105.

Arcova, F.C.S.; Cicco, V.; Rocha, P.A.B. 2003. Precipitação efetiva e interceptação das chuvas por floresta de mata atlântica em uma microbacia experimental em Cunha - São Paulo. Revista Árvore, Viçosa-MG, v.27, n.2, p.257-262.

Bruijnzeel, L. A. 1990. The hydrological cycle in moist tropical forest. In: Bruijnzeel, L. A. Hydrology of moist tropical forests and effects of conversion: a state of knowledge review. Amsterdam: IAHS. p. 5-38.
Castro, P.S.; Valente, O.F.; Coelho, D.T.; Ramalho, R.S. 1983. Interceptação da chuva por mata natural secundária na região de Viçosa, MG. Revista Árvore. v. 7, n. 1, p. 76-89.

Ferreira da Costa, R.; Costa, A.C.L. da; Meir, P.; Malhi, Y. ; Braga, A.P.; Gonçalves, P.H.L.; Silva Junior, J.A.; Sotta, E.D.; Vale, R.L.; Grace, J.; Fisher, R.A. 2003. Projeto LBA/Esecaflor em Caxiuanã: características, atividades e resultados. In: Seminário de 10 anos de atividades da Estação Científica Ferreira Penna, Caxiuanã, Pará. Belém.

Ferreira, S.J.F.; Luizão, F.J.; Dallarosa, R.L.G. 2005. Precipitação interna e interceptação da chuva em floresta de terra firme submetida à extração seletiva de madeira na Amazônia central. Acta Amazonica. v.35, n.1, p.55-62.

Franken, W.; Leopoldo, P.R.; Matsui, E.; Ribeiro, M.N.G. 1982a. Estudo da interceptação da água da chuva em cobertura florestal Amazônica do tipo terra firme. Acta Amazonica. V.12, N.2, P.327-331.

Franken, W.; Leopoldo, P.R.; Matsui, E.; Ribeiro, M.N.G. 1982b. Interceptaçôes das precipitaçôes em floresta Amazônica de terra firme. Acta Amazonica. v.12, Suplemento, p.15-22.

Gash, J.H.C. 1979. An analytical model of rainfall interception by forests. Quarterly Journal of The Royal Meteorological Society, vol. 105 , n. 443, p. 43-55.

Gash, J.H.C.; Lloyd, C.R.; Lachaud, G. 1995. Estimating sparse forest rainfall interception with an analytical model. Journal of Hydrology, vol. 170, p.79-86.

Germer, S.; Elsenbeer, H.; Moraes, J.M. 2006. Throughfall and temporal trends of rainfall redistribution in an open tropical rainforest, south-western Amazonia (Rondônia, Brazil). Hydrology and Earth System Sciences. vol. 10, p. 383-393.

Holwerda, F; Scatena, F.N.; Bruijnzeel, L.A. 2006. Throughfall in a Puerto Rican lower montane rain forest: A comparison of sampling strategies. Journal of Hydrology, vol. 327, p. 592602.

Horton, R. E. 1919. Rainfall interception. Monthly Weather Review, vol. 47, n. 9, p. 603-623.

Huber, A.J.; Oyarzún, C.E. 1983. Precipitacion neta e intercepcion en un bosque adulto de Pinus Radiata (D. Don). Bosque, vol. 5, p.13-20.

Huber, A.J.; Oyarzún, C.E. 1992. Redistribución de las precipitaciones en un bosque siempreverde del sur de Chile. Turrialba, v.42, p. 192-9.

Jackson, I. J. 1971. Problems of throughfall and interception assessment under tropical forest, Journal of Hydrology, v.12, p. 234-254.

Johnson, R. G. 1990. The interception, throughfall and stemflow in a forest in Highland Scotland and the comparison with other upland forests in the U.K. J. Hidrol. (Amst), v.118, p.281-7.

Leopoldo, P. R. 1981. Aspectos hidrológicos de floresta Amazônica densa na regiāo de Manaus: repartição da chuva e respectivas composiçōes em isótopos estáveis. Tese (Livre - Docência) - Faculdade de Ciências Agronômicas, UNESP, Botucatu, SP. 111p. 
Leopoldo, P.R.; Franken, W.; Salati, E.; Ribeiro, M.N.G. 1987. Towarsd A water balance in the central Amazonian region. Experientia., v.43, n.3, p.222-233.

Lima, P.R.A.; Leopoldo, P.R. 1999. Interceptação de chuva por mata ciliar na região central do Estado de São Paulo. Energia na Agricultura, v. 14, n.3, p.25-33.

Lima, P.R.A. 1998. Retenção de água de chuva por mata ciliar na região central do Estado de São Paulo. Dissertação de Mestrado da Faculdade de Ciências Agronômicas da UNESP, Botucatu, SP. $101 \mathrm{p}$.

Lima, W.P.; Nicolielo, N. 1983. Precipitação efetiva e a interceptação em florestas de Pinheiros tropicais e em uma reserva de cerradão. Revista IPEF, n.24, p.43-46.

Lloyd, C.R.; Marques Filho, A.O. 1988. Spatial variability of throughfall and stemflow mensurements in Amazonian rainforest. Agric. For. Meteorol., v.42, p.63-73.

Moraes, J.C.; Costa, J.P.R.; Rocha, E.J.P.; Silva, I.M.O. 1997. Estudos Hidrometeorológicos na Bacia do Rio Caxiuanã. In: Lisboa, P. L. B. (Org). Cnpq/Museu Paraense Emilio Goeldi, Belém, p.85-95.

Oliveira Júnior, J.C.; Dias, H.C.T. 2005. Precipitação efetiva em fragmento secundário da mata Atlântica. Revista Árvore, ViçosaMg, V.29, N.1, P.9-15.

Oliveira, L.L. 2007. Avaliação da interceptação da precipitação pela vegetação na floresta nacional de Caxiuanã, Pará. Dissertação de Mestrado. Universidade Federal de Campina Grande - UFCG, Campina Grande, PB, 123p.

Price, N.W. 1982. A comparison of water balance components in natural and plantation forests in El Salvador, central America. Turrialba, v.32, p.399- 416.

Ruivo, M.L.P.; Pereira, S. B.; Bussetti, E.P.C.; Ferreira da Costa, R.; Quanz, B.; Nagaishi, T.Y.; Oliveira, P.J.; Meir, P.; Malhi, Y.; Costa, A.C.L. Grace, J. 2002. Propriedades do solo e fluxos de $\mathrm{CO}_{2}$ em Caxiuanã, Pará: experimento LBA-ESECAFLOR. In. contribuiçoes a geologia da Amazonia, v.3, (CGA-3), Sociedade Brasileira de Geologia, Belém, ISBN: 95-88692-02-3. p. $291-$ 299.

Rutter, A.J., Kershaw, K.A., Robins, P.C., Morton, A.J. 1971. A predictive model of rainfall interception in forests, $\mathrm{i}$ derivation of the model from observations in a plantation of corsican pine. Agriculture Meteorology, 9, p. 367-384.
Rutter, A.J., Morton, A.J., Robins, P.C. 1975. A predictive model of rainfall interception in forests, ii generalization of the model and comparison with observations in some coniferous and hardwood stands. Journal Of Applied. Ecology, 14, P.567-588.

Schubart, H.O.R.; Franken, W.; Luizão, F.J. 1984. Uma floresta sobre solos pobres. Ciência hoje. v.2, n.10, p.26-32.

Silva, A.S.L.; Almeida, S.S.; Rosário, C.S. 2003. Flórula fanerogâmica da Estação Científica Ferreira Penna (ECFPN): Caracterização dos ecossistemas e lista preliminar de espécies. In: Seminário de 10 anos de atividades da Estação Científica Ferreira Penna, Caxiuanã, Pará. Belém.

Souza, E.P.P. 2003. Relações entre as anomalias de TSM do Atlântico e Pacífico e as precipitações na Amazônia oriental. Dissertação de Mestrado. Instituto Nacional de Pesquisas Espaciais INPE, São José dos Campos, SP (INPE-11435 - TDI/955), 78p.

Tucci, E.M. 2004. Hidrologia ciência e aplicação. In: Tucci, E.M. Hidrologia ciência e aplicação. $3^{\mathrm{a}}$.Ed. Porto Alegre, Editora da UFRGS, ABRH, v.3, p.25-31. 944pp.

Ubarana, V.N. 1994. Experimentos observacionais e modelagem das perdas por interceptação da precipitação na floresta Amazônica. Dissertação de Mestrado. Instituto Nacional de Pesquisas Espaciais-INPE 5583TDI/545. São José dos Campos, SP. Brasil.

Ubarana, V.N. 1996. Observation and modelline of raifall interception at two experimental sites in Amazônia. Amazônian deforestation and climate. p.151-162.

Viana, J. S.; Almeida, S. S.; Conceição, C.; Ferreira, E.; Alves, N.E.; Silva, R. 2003. Comparação estrutural e florística entre os ambientes de terra-firme e igapó do entorno da Estação Científica Ferreira Penna - ECFPn. In: Seminário de 10 anos de atividades da Estação Científica Ferreira Penna, Caxiuanã, Pará. Belém.

Villela, S. M.; Mattos, A. 1975. Hidrologia Aplicada. McGraw-Hill do Brasil, São Paulo, 245pp.

Rcebido em 08/03/2007

Aceito em 25/09/2008 